\title{
The Current Conditions and Lifestyles of Obese University Students
}

\author{
Natsumi Morito ${ }^{\mathrm{a}}$, Yasunori Suematsu ${ }^{\mathrm{b}}$, Rie Koyoshic, Yuhei Shiga ${ }^{\mathrm{b}}$, Takashi Kuwano ${ }^{\mathrm{b}}$, \\ Atsushi Iwata ${ }^{b}$, Kanta Fujimi ${ }^{\text {b, d }}$, Akira Kawamurab, e, Shin-ichiro Miurab, f, g
}

\begin{abstract}
Background: The prevalence of cardiovascular diseases in Japan remains high, and the onset becomes early. Studies on the current conditions and lifestyles of obese university students may support early interventions to achieve lifestyle modification.
\end{abstract}

Methods and Results: The results of periodic health examinations in 32,262 first-year university students revealed that 2,036 (6.3\%) were obese. We performed a more detailed examination in 221 of these obese students (165 males and 56 females, age $19 \pm 1$ years) with study agreement from 2014 to 2016. In this study cohort, the percentage of students who exercised regularly was significantly higher among males than females. Body fat in males with well-exercised was lower than that in males with no exercise. In addition, serum level of high-density cholesterol in males with well-exercised was higher. Among females, there were no significant differences in these parameters between exercisers and non-exercisers. Forty-two obese students (40 males and two females) met the diagnostic criteria of metabolic syndrome (MetS). Among males, levels of body fat, uric acid, liver enzyme and insulin resistance in the MetS group were significantly higher than those in the non-MetS group. The average ratio of eicosapentaenoic acid to arachidonic acid (EPA/AA) was low (0.14).

Conclusions: Although the proportions of students with obesity and/ or MetS were not high, the EPA/AA ratio in obese young males was low, which may be associated with a high risk of coronary atherosclerosis. To prevent the onset of cardiovascular diseases early interven-

Manuscript submitted December 18, 2017, accepted January 16, 2018

${ }^{a}$ Fukuoka University Health Care Center, Fukuoka, Japan

bepartment of Cardiology, Fukuoka University School of Medicine, Fukuoka, Japan

${ }^{\mathrm{c} D i v i s i o n}$ of Medical Safety Management, Fukuoka University Hospital, Fukuoka, Japan

${ }^{\mathrm{d} D e p a r t m e n t ~ o f ~ R e h a b i l i t a t i o n, ~ F u k u o k a ~ U n i v e r s i t y ~ H o s p i t a l, ~ F u k u o k a, ~ J a p a n ~}$ ePost-Graduate Education Center, Fukuoka University Hospital, Fukuoka, Japan

fDepartment of Molecular Cardiovascular Therapeutics, Fukuoka University School of Medicine, Fukuoka, Japan

gCorresponding Author: Shin-ichiro Miura, Department of Cardiology, Fukuoka University School of Medicine, 7-45-1 Nanakuma, Jonan-Ku, Fukuoka, 814-0180, Japan. Email miuras@cis.fukuoka-u.ac.jp

doi: https://doi.org/10.14740/jocmr3329w tion to achieve lifestyle modification may be important.

Keywords: Lifestyle-related diseases; University students; Cardiovascular disease; Lifestyle modification

\section{Introduction}

The prevalence of cardiovascular disease (CVD) in Japan is still high, and the prevalence of lifestyle-related diseases that are risk factors for CVD is also increasing [1]. In addition, lifestyle-related diseases are showing an increasingly younger age of onset, and thus are becoming a major social problem. In a survey conducted by the Ministry of Education, Culture, Sports, Science and Technology, over the past 30 years, the proportion of obesity among children has increased rapidly, and one of 10 Japanese males aged 9 to 17 years is now estimated to be obese [2]. This is believed to be due to changes in eating disorders and lifestyle habits. Unhealthy lifestyle habits continue when students enters university where they face a high possibility of further deterioration. Therefore, interventions to raise awareness regarding the association between lifestyle habits and obesity at the time of admission to university may be useful for the prevention and early onset of lifestylerelated diseases. The purpose of this research was to determine the current prevalence of obesity in university students, along with the presence or absence of metabolic syndrome (MetS), and the associations between obesity and lifestyle habits or biochemical parameters.

\section{Methods}

\section{Subjects and data collection}

We used data obtained at mandatory periodic health checkups at Fukuoka University. The subjects were first-year university students from 2010 to 2016 . Obesity was defined as body mass index $(\mathrm{BMI})>25 \mathrm{~kg} / \mathrm{m}^{2}(\mathrm{BMI}>26.5$ from 2010 to 2013). More detailed examinations (blood tests, etc.) were performed when the student consented to these examinations. We analyzed lifestyle habits by a questionnaire and performed a detailed examination (body height (BH), body weight (BW), BMI, abdominal circumference (AC), body fat, smoking hab- 


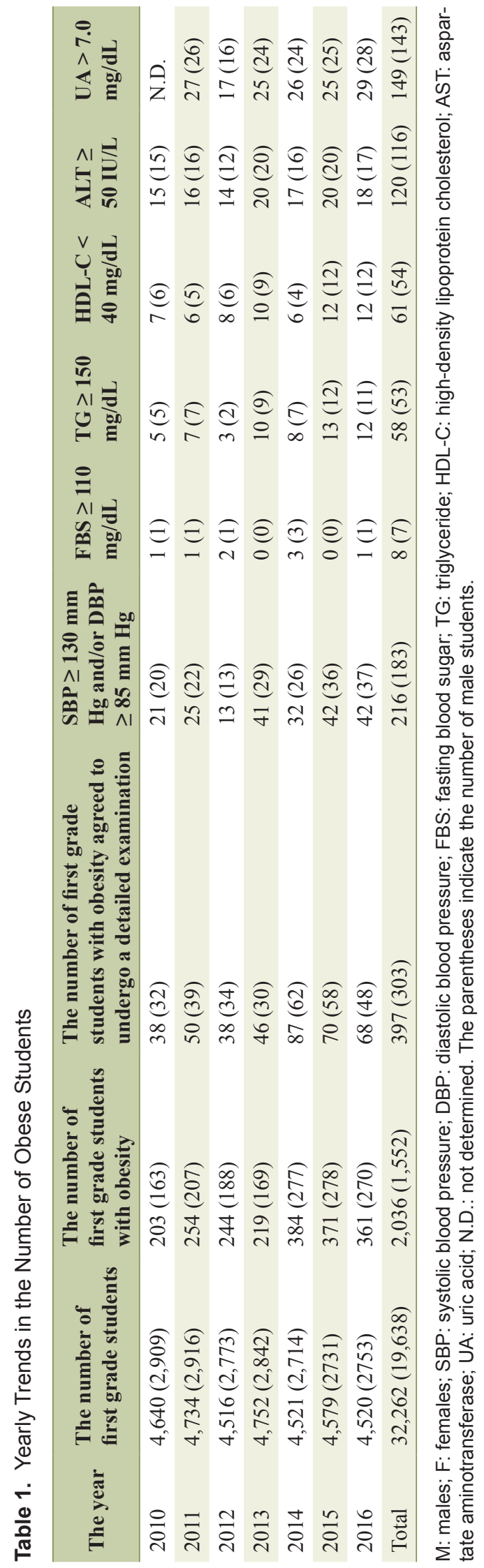

its, exercise status, systolic blood pressure (SBP), diastolic blood pressure (DBP), white blood cell count (WBC), red blood cell count (RBC), the eicosapentaenoic acid to arachidonic acid ratio (EPA/AA), homeostasis model assessment-insulin resistance (HOMA-IR), and blood levels of hemoglobin $(\mathrm{Hb})$, platelet (PLT), blood urea nitrogen (BUN), creatinine $(\mathrm{Cr})$, uric acid (UA), aspartate aminotransferase (AST), alanine aminotransferase (ALT), $\gamma$-glutamyltranspeptidase $(\gamma \mathrm{GTP})$, total cholesterol (TC), triglyceride (TG), high-density lipoprotein cholesterol (HDL-C), low-density lipoprotein cholesterol (LDL-C), sodium (Na), potassium (K), fasting blood sugar (FBS), insulin (IRI), hemoglobin A1c (HbA1c), high-sensitive $\mathrm{C}$-reactive protein (hCRP) and adiponectin). Smoking habits were defined as currently smoking or parents who smoked. The protocol in this study was approved by the Ethics Committee of Fukuoka University School of Medicine. All data were retrospectively collected from the database of Fukuoka University Health Care Center.

\section{Statistical analysis}

Statistical analysis was performed using Excel (Version 14.2.0; Microsoft Corp., Redmond, WA). Data are expressed as mean \pm standard deviation (SD). Categorical and continuous variables were compared between groups by Chi-square analysis and Student's $t$-test, respectively. A value of $\mathrm{P}<0.05$ was considered significant.

\section{Results}

\section{Yearly trends in the number of obese students}

The total number of first-year students from 2010 to 2016 was 32,262 (19,638 male and 12,624 female) (Table 1). Among them, 2,036 (6.3\%) were obese (1,552 male (7.9\%) and 484 female $(3.8 \%)$ ). Of these obese students, 397 (about 20\%) agreed to undergo a detailed examination (303 male and 94 female) (Table 1). The numbers (percentages) of students who had $\mathrm{SBP} \geq 130 \mathrm{~mm} \mathrm{Hg}$ and/or DBP $\geq 85 \mathrm{~mm} \mathrm{Hg}, \mathrm{FBS} \geq 110$ $\mathrm{mg} / \mathrm{dL}, \mathrm{TG} \geq 150 \mathrm{mg} / \mathrm{dL}, \mathrm{HDL}-\mathrm{C}<40 \mathrm{mg} / \mathrm{dL}$, ALT $\geq 50 \mathrm{IU} / \mathrm{L}$ and UA > $7.0 \mathrm{mg} / \mathrm{dL}$ were 216 (54.4\%), 8 (2.0\%), 58 (14.6 $\%), 61(15.4 \%), 120(30.2 \%)$ and $149(37.5 \%)$, respectively (Fig. 1).

\section{Characteristics of and biochemical parameters in blood of obese students: all students, males and females}

Since there were changes in the detailed examination items, such as in the definition of BMI and the contents of the questionnaire, from 2010 to 2016, we only included obese students from 2014 to 2016, when there were no changes. We excluded students who were 30 years of age or older and those who played sports almost every day. Finally, we considered 221 obese students (165 males and 56 females) for further analysis (Fig. 1, Table 2). The average ages of males and females 


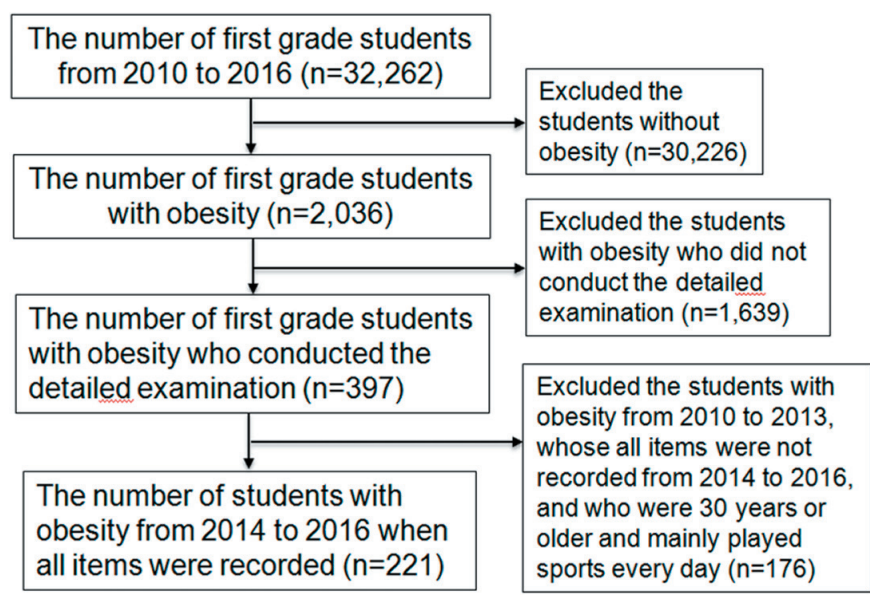

Figure 1. Flow diagram of first-year students.

were $19 \pm 1$ and $18 \pm 1$ years, respectively. While males had significantly higher $\mathrm{BH}, \mathrm{BW}$ and $\mathrm{AC}$ compared to females, females had higher body fat. There was no significant difference in BMI between males $\left(31 \pm 4 \mathrm{~kg} / \mathrm{m}^{2}\right)$ and females $(30 \pm 4 \mathrm{~kg} /$ $\mathrm{m}^{2}$ ). SBP and DBP in males were significantly higher than those in females. Liver and kidney function and UA levels in males were significantly higher than those in females. Regarding lipid metabolism, males showed significantly higher TG and LDL-C levels than females. All of the obese students had a low EPA/AA ratio, but there was no gender difference. There were also no gender differences in levels of FBS, IRI, HbAlc or hCRP. However, adiponectin levels in obese males were significantly lower than those in obese females.

\section{Characteristics of and various biochemical parameters in blood of obese students: in quartiles according to BMI}

Next, the obese students were divided into four groups (Q, quartiles) according to BMI (Q1 $(\mathrm{n}=56), \mathrm{BMI}<27.6$; Q2 ( $=$ 56), 27.6 $\leq \mathrm{BMI}<31$; Q3 $(\mathrm{n}=56), 31 \leq \mathrm{BMI}<33.2$; and $\mathrm{Q} 4$ $(\mathrm{n}=53), 33.2 \leq \mathrm{BMI})$ (Table 3). BW, AC, body fat, SBP, DBP, WBC, RBC, PLT, UA, AST, ALT, $\gamma$ GTP, TG, LDL-C, FBS, IRI, HOMA-IR and hCRP all significantly increased as BMI increased. HDL-C and adiponectin significantly decreased as BMI increased.

Characteristics of and various biochemical parameters in blood of obese students: exercise and non-exercise groups in males and females

The obese students were divided into males and females with or without exercise habits (Table 4) based on the questionnaire. The exercise group was defined as students who exercised for more than 30 min at least twice a week other than school attendance. Among both males and females, body fat in the non-exercise group was significantly higher than that in the exercise group. Among males, HDL-C in the non-exercise group was significantly lower than that in the exercise
Table 2. Characteristics of and Various Biochemical Parameters in Blood of Obese Students: All Students, Males and Females

\begin{tabular}{|c|c|c|c|}
\hline & All & Males & Females \\
\hline $\mathrm{N}$ & 221 & 165 & 56 \\
\hline Age (years) & $19 \pm 1$ & $19 \pm 1$ & $18 \pm 1$ \\
\hline $\mathrm{BH}(\mathrm{cm})$ & $167 \pm 8$ & $171 \pm 6$ & $158 \pm 5^{* *}$ \\
\hline BW (kg) & $86 \pm 14$ & $90 \pm 12$ & $74 \pm 14 * *$ \\
\hline BMI $\left(\mathrm{kg} / \mathrm{m}^{2}\right)$ & $31 \pm 4$ & $31 \pm 4$ & $30 \pm 4$ \\
\hline $\mathrm{AC}(\mathrm{cm})$ & $95 \pm 10$ & $97 \pm 10$ & $90 \pm 10 * *$ \\
\hline Body fat (\%) & $32 \pm 7$ & $30 \pm 7$ & $38 \pm 5 * *$ \\
\hline Non-smoking (\%) & 67 & 68 & 66 \\
\hline Exercise (\%) & 32 & 38 & $18^{*}$ \\
\hline SBP (mm Hg) & $135 \pm 13$ & $137 \pm 12$ & $127 \pm 13 * *$ \\
\hline DBP (mm Hg) & $72 \pm 11$ & $73 \pm 11$ & $69 \pm 10^{*}$ \\
\hline WBC $(/ \mu \mathrm{L})$ & $7,163 \pm 1,703$ & $7,001 \pm 1,657$ & $7641 \pm 1761^{*}$ \\
\hline $\mathrm{RBC}\left(\times 10^{4} / \mu \mathrm{L}\right)$ & $516 \pm 38$ & $530 \pm 29$ & $473 \pm 27 * *$ \\
\hline $\mathrm{Hb}(\mathrm{g} / \mathrm{dL})$ & $15 \pm 1$ & $16 \pm 1$ & $14 \pm 1 * *$ \\
\hline $\operatorname{PLT}\left(\times 10^{4} / \mu \mathrm{L}\right)$ & $28 \pm 5$ & $27 \pm 5$ & $30 \pm 6^{* *}$ \\
\hline BUN (mg/dL) & $12 \pm 3$ & $12 \pm 3$ & $10 \pm 2 * *$ \\
\hline $\mathrm{Cr}(\mathrm{mg} / \mathrm{dL})$ & $0.8 \pm 0.1$ & $0.9 \pm 0.1$ & $0.6 \pm 0.1 * *$ \\
\hline $\mathrm{UA}(\mathrm{mg} / \mathrm{dL})$ & $6.5 \pm 1.6$ & $7.0 \pm 1.5$ & $5.2 \pm 1.1 * *$ \\
\hline AST (IU/L) & $27 \pm 16$ & $30 \pm 17$ & $20 \pm 6^{* *}$ \\
\hline ALT (IU/L) & $44 \pm 41$ & $51 \pm 44$ & $24 \pm 17 * *$ \\
\hline$\gamma \mathrm{GTP}(\mathrm{IU} / \mathrm{L})$ & $33 \pm 26$ & $37 \pm 28$ & $21 \pm 9 * *$ \\
\hline TC (mg/dL) & $182 \pm 31$ & $183 \pm 33$ & $178 \pm 22$ \\
\hline TG (mg/dL) & $104 \pm 70$ & $111 \pm 76$ & $83 \pm 44^{*}$ \\
\hline HDL-C (mg/dL) & $50 \pm 10$ & $49 \pm 9$ & $55 \pm 10 * *$ \\
\hline LDL-C (mg/dL) & $116 \pm 28$ & $118 \pm 30$ & $109 \pm 21^{*}$ \\
\hline EPA/AA & $0.14 \pm 0.07$ & $0.15 \pm 0.07$ & $0.13 \pm 0.07$ \\
\hline $\mathrm{Na}(\mathrm{mEq} / \mathrm{L})$ & $141 \pm 7$ & $141 \pm 2$ & $139 \pm 14^{*}$ \\
\hline $\mathrm{K}(\mathrm{mE} / \mathrm{dL})$ & $3.8 \pm 0.3$ & $3.8 \pm 0.3$ & $3.8 \pm 0.3$ \\
\hline FBS (mg/dL) & $87 \pm 8$ & $88 \pm 9$ & $86 \pm 6$ \\
\hline IRI & $12 \pm 6$ & $12 \pm 8$ & $12 \pm 5$ \\
\hline $\mathrm{HbA} 1 \mathrm{c}(\%)$ & $5.2 \pm 0.3$ & $5.2 \pm 0.3$ & $5.2 \pm 0.3$ \\
\hline HOMA-IR & $2.6 \pm 2.0$ & $2.7 \pm 2.2$ & $2.6 \pm 1.2$ \\
\hline hCRP (ng/mL) & $1,773 \pm 2,926$ & $1,648 \pm 2,711$ & $2,146 \pm 3,492$ \\
\hline Adiponection & $6.4 \pm 2.4$ & $6.0 \pm 2.2$ & $7.6 \pm 2.7^{*}$ \\
\hline
\end{tabular}

$\mathrm{BH}$ : body height; BW: body weight; BMl: body mass index; $\mathrm{AC}$ : abdominal circumference; SBP: systolic blood pressure; DBP: diastolic blood pressure; WBC: white blood cell; RBC: red blood cell; $\mathrm{Hb}$ : hemoglobin; PLT: platelet; BUN: blood urea nitrogen; Cr: creatine; UA: uric acid; AST: aspartate aminotransferase; ALT: alanine aminotransferase; YGTP: $\gamma$-glutamyltranspeptidase; TC: total cholesterol; TG: triglyceride; HDL-C: high-density lipoprotein cholesterol; LDL-C: low density lipoprotein cholesterol; EPA/AA: the ratio of eicosapentaenoic acid to arachidonic acid; Na: sodium; K: potassium; FBS: blood sugar; IRI: insulin; HbA1c: hemoglobin A1c; HOMA-IR: homeostasis model assessmentinsulin resistance; hCRP: high sensitive $C$-reactive protein. ${ }^{*} \mathrm{P}<0.05$, ${ }^{* *} \mathrm{P}<0.01$ vs. Males. 
Table 3. Characteristics of and Various Biochemical Parameters in Blood of Obese Students: in Quartiles According to BMI

\begin{tabular}{|c|c|c|c|c|c|}
\hline & Q1 & Q2 & Q3 & Q4 & P for trend \\
\hline $\mathrm{N}$ & 56 & 56 & 56 & 53 & \\
\hline Age (years) & $19 \pm 1$ & $19 \pm 1$ & $19 \pm 1$ & $19 \pm 1$ & NS \\
\hline $\mathrm{BH}(\mathrm{cm})$ & $166 \pm 8$ & $167 \pm 8$ & $168 \pm 8$ & $169 \pm 7$ & NS \\
\hline BW (kg) & $72 \pm 7$ & $83 \pm 9$ & $90 \pm 8$ & $99 \pm 16$ & $<0.005$ \\
\hline Body fat (\%) & $26 \pm 7$ & $31 \pm 5$ & $34 \pm 6$ & $37 \pm 5$ & $<0.005$ \\
\hline Non-smoking (\%) & $34: 6 \%$ & $42: 8 \%$ & $34: 6 \%$ & $36: 7 \%$ & NS \\
\hline Exercise $(\%)$ & $22: 4 \%$ & $20: 4 \%$ & $12: 2 \%$ & $18: 4 \%$ & NS \\
\hline $\mathrm{SBP}(\mathrm{mm} \mathrm{Hg})$ & $128 \pm 14$ & $137 \pm 13$ & $134 \pm 12$ & $140 \pm 12$ & $<0.005$ \\
\hline $\mathrm{Hb}(\mathrm{g} / \mathrm{dL})$ & $15 \pm 1$ & $15 \pm 1$ & $15 \pm 1$ & $15 \pm 1$ & NS \\
\hline $\operatorname{PLT}\left(\times 10^{4} / \mu \mathrm{L}\right)$ & $26 \pm 5$ & $28 \pm 6$ & $28 \pm 5$ & $29 \pm 5$ & $<0.005$ \\
\hline BUN (mg/dL) & $12 \pm 2$ & $12 \pm 3$ & $12 \pm 3$ & $11 \pm 3$ & NS \\
\hline $\mathrm{Cr}(\mathrm{mg} / \mathrm{dL})$ & $0.8 \pm 0.1$ & $0.8 \pm 0.1$ & $0.8 \pm 0.1$ & $0.8 \pm 0.1$ & NS \\
\hline $\mathrm{UA}(\mathrm{mg} / \mathrm{dL})$ & $5.6 \pm 1.3$ & $6.5 \pm 1.5$ & $6.9 \pm 1.4$ & $7.3 \pm 1.6$ & $<0.005$ \\
\hline AST (IU/L) & $20 \pm 5$ & $27 \pm 18$ & $29 \pm 17$ & $33 \pm 16$ & $<0.005$ \\
\hline ALT (IU/L) & $22 \pm 12$ & $45 \pm 48$ & $53 \pm 45$ & $59 \pm 40$ & $<0.005$ \\
\hline$\gamma \mathrm{GTP}(\mathrm{IU} / \mathrm{L})$ & $23 \pm 14$ & $30 \pm 22$ & $40 \pm 28$ & $40 \pm 32$ & $<0.005$ \\
\hline $\mathrm{TC}(\mathrm{mg} / \mathrm{dL})$ & $177 \pm 27$ & $182 \pm 29$ & $190 \pm 34$ & $181 \pm 33$ & NS \\
\hline FBS (mg/dL) & $84 \pm 5$ & $87 \pm 7$ & $89 \pm 9$ & $89 \pm 9$ & $<0.005$ \\
\hline IRI $(\mu \mathrm{IU} / \mathrm{mL})$ & $8 \pm 4$ & $12 \pm 9$ & $12 \pm 8$ & $16 \pm 6$ & $<0.005$ \\
\hline HbAlc $(\%)$ & $5.2 \pm 0.2$ & $5.2 \pm 0.4$ & $5.2 \pm 0.3$ & $5.3 \pm 0.3$ & NS \\
\hline HOMA-IR & $1.7 \pm 0.8$ & $2.6 \pm 2.2$ & $2.8 \pm 2.6$ & $3.5 \pm 1.5$ & $<0.005$ \\
\hline hCRP (ng/mL) & $718 \pm 1,562$ & $1,492 \pm 2,694$ & $1,523 \pm 1,998$ & $3,503 \pm 4,195$ & $<0.005$ \\
\hline Adiponectin $(\mu \mathrm{g} / \mathrm{mL})$ & $7.3 \pm 2.2$ & $6.2 \pm 2.4$ & $6.4 \pm 3.0$ & $5.5 \pm 1.8$ & $<0.005$ \\
\hline
\end{tabular}

group.

\section{Characteristics of and various biochemical parameters in blood of obese students: smoking and non-smoking groups}

Characteristics of and various biochemical parameters in blood of obese students in the smoking and non-smoking groups are shown in Table 5. Sixty-four students were classified in the smoking group, only one of whom was currently smoking. The remaining 63 students had parents who smoked. The TC, TG and LDL-C levels in the smoking group were significantly higher than those in the non-smoking group.

Characteristics of and various biochemical parameters in blood of obese male students: MetS and non-MetS groups

Forty-two (40 males and two females) of the 221 obese stu- 
Table 4. Characteristics of and Various Biochemical Parameters in Blood of Obese Students: Exercise and Non-Exercise Groups in Males and Females

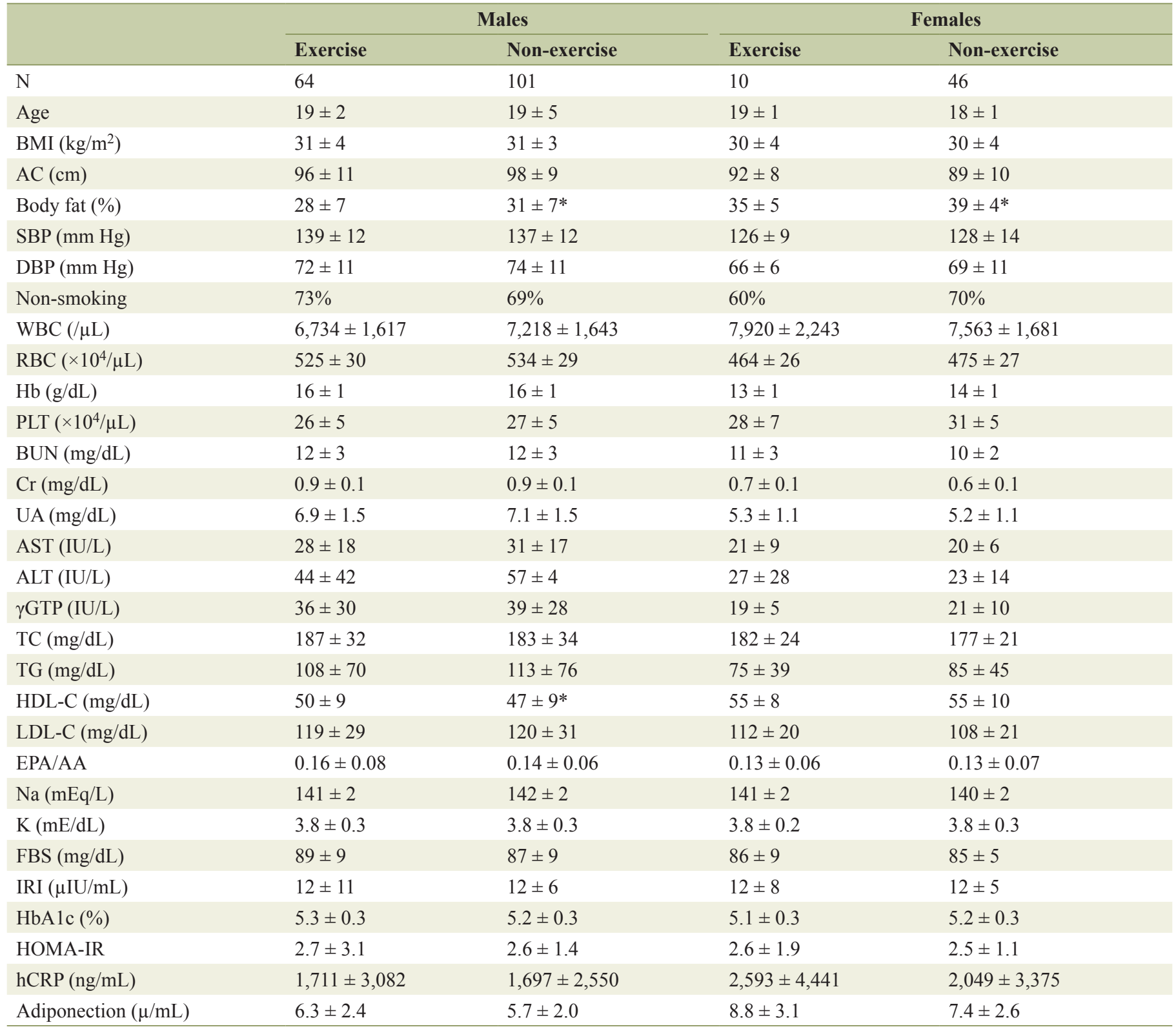

${ }^{*} \mathrm{P}<0.01$ vs. Exercise.

dents met the diagnostic criteria for MetS (MetS group). We excluded females from this analysis because there were only two (Table 6). BW, BMI, AC, body fat, SBP, WBC, RBC, Hb, PLT, UA, liver function, TG, IRI, and HOMA-IR in the MetS group were significantly higher than those in the non-MetS group. The MetS group also had significantly lower HDL-C and adiponectin levels than the non-MetS group.

\section{Discussion}

In this study, obese students comprised $6.3 \%$ of the total. Ac- cording to the Annual Health, Labour and Welfare Report 2014 [1], the prevalence of obesity among people in their $20 \mathrm{~s}$ in $2012(15.2 \%)$ was much higher than that of 30 years ago $(9.8$ $\%)$. With regard to an awareness of the importance of lifestyle for health, while a high proportion of people over age 65 years (69\%) were "positively doing things or being particularly attentive" or "being careful about lifestyle", people aged 20 to 39 years were less likely to be concerned about their lifestyle (44.8\%). Young people with MetS are at an increased risk of type 2 diabetes mellitus [3]. Although the proportion of Japanese students with obesity and/or MetS is not particularly high, both of these conditions are considered to be risk factors for 
Table 5. Characteristics of and Various Biochemical Parameters in Blood of Obese Students: Smoking and Non-Smoking Groups

\begin{tabular}{|c|c|c|}
\hline & Smoking & Non-smoking \\
\hline $\mathrm{N}$ & 64 & 157 \\
\hline Age & $19 \pm 1$ & $19 \pm 4$ \\
\hline Males (\%) & 73 & 75 \\
\hline BMI $\left(\mathrm{kg} / \mathrm{m}^{2}\right)$ & $31 \pm 3$ & $31 \pm 4$ \\
\hline $\mathrm{AC}(\mathrm{cm})$ & $95 \pm 10$ & $95 \pm 11$ \\
\hline Body fat (\%) & $32 \pm 7$ & $32 \pm 8$ \\
\hline SBP (mm Hg) & $134 \pm 14$ & $136 \pm 12$ \\
\hline DBP (mm Hg) & $72 \pm 11$ & $72 \pm 11$ \\
\hline Exercise (\%) & 33 & 35 \\
\hline $\mathrm{WBC}(/ \mu \mathrm{L})$ & $7,484 \pm 1,668$ & $7,035 \pm 1,696$ \\
\hline $\mathrm{RBC}\left(\times 10^{4} / \mu \mathrm{L}\right)$ & $514 \pm 40$ & $516 \pm 38$ \\
\hline $\mathrm{Hb}(\mathrm{g} / \mathrm{dL})$ & $15 \pm 1$ & $15 \pm 1$ \\
\hline $\operatorname{PLT}\left(\times 10^{4} / \mu \mathrm{L}\right)$ & $28 \pm 5$ & $27 \pm 5$ \\
\hline BUN (mg/dL) & $12 \pm 3$ & $11 \pm 3$ \\
\hline $\mathrm{Cr}(\mathrm{mg} / \mathrm{dL})$ & $0.8 \pm 0.1$ & $0.8 \pm 0.1$ \\
\hline $\mathrm{UA}(\mathrm{mg} / \mathrm{dL})$ & $6.6 \pm 1.5$ & $6.5 \pm 1.6$ \\
\hline AST (IU/L) & $28 \pm 16$ & $27 \pm 16$ \\
\hline ALT (IU/L) & $46 \pm 44$ & $44 \pm 41$ \\
\hline$\gamma \mathrm{GTP}(\mathrm{IU} / \mathrm{L})$ & $35 \pm 32$ & $33 \pm 23$ \\
\hline $\mathrm{TC}(\mathrm{mg} / \mathrm{dL})$ & $191 \pm 29$ & $179 \pm 31^{*}$ \\
\hline $\mathrm{TG}(\mathrm{mg} / \mathrm{dL})$ & $113 \pm 81$ & $100 \pm 62 *$ \\
\hline HDL-C (mg/dL) & $52 \pm 11$ & $50 \pm 9$ \\
\hline LDL-C (mg/dL) & $122 \pm 29$ & $114 \pm 28^{*}$ \\
\hline EPA/AA & $0.14 \pm 0.07$ & $0.14 \pm 0.07$ \\
\hline $\mathrm{Na}(\mathrm{mEq} / \mathrm{L})$ & $141 \pm 2$ & $141 \pm 9$ \\
\hline $\mathrm{K}(\mathrm{mE} / \mathrm{dL})$ & $3.8 \pm 0.3$ & $3.8 \pm 0.3$ \\
\hline FBS (mg/dL) & $88 \pm 9$ & $87 \pm 8$ \\
\hline IRI $(\mu \mathrm{IU} / \mathrm{mL})$ & $11 \pm 5$ & $12 \pm 8$ \\
\hline HbAlc (\%) & $5.2 \pm 0.3$ & $5.2 \pm 0.3$ \\
\hline HOMA-IR & $2.5 \pm 1.5$ & $2.7 \pm 2.3$ \\
\hline hCRP (ng/mL) & $1,597 \pm 1,086$ & $1,919 \pm 2,932$ \\
\hline Adiponection $(\mu / \mathrm{mL})$ & $6.5 \pm 2.7$ & $6.3 \pm 2.4$ \\
\hline
\end{tabular}

${ }^{*} \mathrm{P}<0.05$ vs. Smoking.

CVD.

This study was limited to obese students. Overall, $33 \%$ of the obese students exercised regularly, and there was a significant difference in exercise habits between males $(63 \%)$ and females $(22 \%)$. Since the questionnaire provided selfreported data, it is impossible to confirm differences, such as in exercise intensity between the two groups. In addition, the only parameter that significantly differed between the exercise and non-exercise groups was body fat. Obese males who exercised had significantly higher HDL-C levels than non-
Table 6. Characteristics of and Various Biochemical Parameters in Blood of Obese Male Students: MetS and Non-MetS Groups

\begin{tabular}{|c|c|c|}
\hline & Mets & Non-Mets \\
\hline $\mathrm{N}$ & 40 & 125 \\
\hline Age & $19 \pm 2$ & $19 \pm 1$ \\
\hline $\mathrm{BH}(\mathrm{cm})$ & $172 \pm 6$ & $170 \pm 6$ \\
\hline BW (kg) & $96 \pm 9$ & $88 \pm 12 * *$ \\
\hline BMI $\left(\mathrm{kg} / \mathrm{m}^{2}\right)$ & $32 \pm 3$ & $30 \pm 4 * *$ \\
\hline $\mathrm{AC}(\mathrm{cm})$ & $101 \pm 6$ & $95 \pm 10 * *$ \\
\hline Body fat (\%) & $32 \pm 4$ & $29 \pm 8^{*}$ \\
\hline $\mathrm{SBP}(\mathrm{mm} \mathrm{Hg})$ & $141 \pm 9$ & $136 \pm 13^{*}$ \\
\hline DBP(mm Hg) & $75 \pm 10$ & $72 \pm 11$ \\
\hline Non-smoking (\%) & 60 & 69 \\
\hline Exercise (\%) & 30 & 42 \\
\hline WBC $(/ \mu \mathrm{L})$ & $7,727 \pm 1,483$ & $6,769 \pm 1,648 * *$ \\
\hline $\mathrm{RBC}\left(\times 10^{4} / \mu \mathrm{L}\right)$ & $544 \pm 27$ & $526 \pm 29 * *$ \\
\hline $\mathrm{Hb}(\mathrm{g} / \mathrm{dL})$ & $16 \pm 1$ & $15 \pm 1 * *$ \\
\hline $\operatorname{PLT}\left(\times 10^{4} / \mu \mathrm{L}\right)$ & $28 \pm 4$ & $26 \pm 5^{*}$ \\
\hline BUN (mg/dL) & $12 \pm 3$ & $13 \pm 3$ \\
\hline $\mathrm{Cr}(\mathrm{mg} / \mathrm{dL})$ & $0.9 \pm 0.1$ & $0.9 \pm 0.1$ \\
\hline UA (mg/dL) & $7.4 \pm 1.3$ & $6.9 \pm 1.5^{*}$ \\
\hline AST (IU/L) & $37 \pm 22$ & $27 \pm 14 * *$ \\
\hline $\operatorname{ALT}(\mathrm{IU} / \mathrm{L})$ & $76 \pm 59$ & $43 \pm 35^{* *}$ \\
\hline$\gamma \mathrm{GTP}(\mathrm{IU} / \mathrm{L})$ & $52 \pm 36$ & $33 \pm 24 * *$ \\
\hline $\mathrm{TC}(\mathrm{mg} / \mathrm{dL})$ & $192 \pm 39$ & $181 \pm 31$ \\
\hline TG (mg/dL) & $191 \pm 101$ & $86 \pm 42 * *$ \\
\hline HDL-C (mg/dL) & $41 \pm 6$ & $51 \pm 9 * *$ \\
\hline LDL-C (mg/dL) & $125 \pm 35$ & $116 \pm 28$ \\
\hline EPA/AA & $0.14 \pm 0.07$ & $0.15 \pm 0.07$ \\
\hline $\mathrm{Na}(\mathrm{mEq} / \mathrm{L})$ & $141 \pm 2$ & $141 \pm 2$ \\
\hline $\mathrm{K}(\mathrm{mE} / \mathrm{dL})$ & $3.7 \pm 0.3$ & $3.8 \pm 0.3$ \\
\hline FBS (mg/dL) & $89 \pm 11$ & $87 \pm 8$ \\
\hline IRI $(\mu \mathrm{IU} / \mathrm{mL})$ & $15 \pm 11$ & $11 \pm 7 * *$ \\
\hline $\mathrm{HbA} 1 \mathrm{c}(\%)$ & $5.3 \pm 0.3$ & $5.2 \pm 0.3$ \\
\hline HOMA-IR & $3.4 \pm 2.7$ & $2.4 \pm 2.0^{*}$ \\
\hline hCRP (ng/mL) & $2,081 \pm 3,137$ & $1,511 \pm 2,561$ \\
\hline Adiponection $(\mu / \mathrm{mL})$ & $5.1 \pm 1.5$ & $6.2 \pm 2.3^{* *}$ \\
\hline
\end{tabular}

${ }^{*} \mathrm{P}<0.05,{ }^{* *} \mathrm{P}<0.01$ vs. Mets.

exercisers.

Smoking habits were determined using a questionnaire. Only one of the obese students smoked. There are several reports that parents who smoke influence their children $[4,5]$. According to a report from Finland [4], children with parents who smoke show a greater progression of carotid plaque than children whose parents do not smoke. Since a smoking par- 
ent may influence the risk of arteriosclerosis in their children, we compared students with parents who smoked to students whose parents did not smoke. No significant difference in BP or diabetes was noted between the two groups. However, lipid levels, such as total cholesterol, LDL-C and TG, in the smoking group were significantly higher than those in the nonsmoking group, which is consistent with the previous report.

A low EPA/AA ratio has been associated with a high risk of coronary atherosclerosis [5, 6]. Maintaining a high EPA/ AA ratio through the administration of EPA has been shown to be effective for preventing cardiovascular events [7]. In this study, the EPA/AA ratio in obese subjects was very low (0.14). In addition, there were no significant associations between EPA/AA and gender, severity of obesity, or presence of MetS in males. While there have been few reports on the EPA/ AA ratio in young subjects, this ratio increases with age [8]. A recent report stated that low EPA/AA values are related to the risk of other diseases as well as CVD [9-11]. These results may be influenced by changes in modern dietary habits, and may contribute to the early onset of arteriosclerosis.

This study has several limitations. First, the study was cross-sectional. Second, some of the data were obtained using a questionnaire, and thus may not be accurate.

In conclusion, the proportion of obese students at our university (about $6 \%$ ) was not particularly high. However, the EPA/AA ratio in young obese males was quite low, which may be associated with a high risk of coronary atherosclerosis. To help prevent the onset of CVD, early intervention may be needed to achieve lifestyle modification.

\section{Conflict of Interest}

This research received no specific grant from any funding agency in the public, commercial, or not-for-profit sectors. S.M. belongs to the Department of Molecular Cardiovascular Therapeutics, which is supported by MSD, Co. LTD.

\section{References}

1. Annual health, labour and welfare report 2014. Ministry of Health, Labour and Welfare. http://www.mhlw.go.jp/ english/wp/wp-hw8/index.html.

2. Annual school health statistics Report 2008. Ministry of Education, Culture, Sports, Science and Technology. http://www.mext.go.jp/b_menu/toukei/chousa05/hoken/ kekka/k_detail/1279370.htm.
3. Magnussen CG, Koskinen J, Juonala M, Chen W, Srinivasan SR, Sabin MA, Thomson R, et al. A diagnosis of the metabolic syndrome in youth that resolves by adult life is associated with a normalization of high carotid intima-media thickness and type 2 diabetes mellitus risk: the Bogalusa heart and cardiovascular risk in young Finns studies. J Am Coll Cardiol. 2012;60(17):1631-1639.

4. West HW, Juonala M, Gall SL, Kahonen M, Laitinen T, Taittonen L, Viikari JS, et al. Exposure to parental smoking in childhood is associated with increased risk of carotid atherosclerotic plaque in adulthood: the Cardiovascular Risk in Young Finns Study. Circulation. 2015;131(14):1239-1246.

5. Juonala M, Magnussen CG, Raitakari OT. Parental smoking produces long-term damage to vascular function in their children. Curr Opin Cardiol. 2013;28(5):569-574.

6. Nagahara Y, Motoyama S, Sarai M, Ito H, Kawai H, Takakuwa Y, Miyagi M, et al. Eicosapentaenoic acid to arachidonic acid (EPA/AA) ratio as an associated factor of high risk plaque on coronary computed tomography in patients without coronary artery disease. Atherosclerosis. 2016;250:30-37.

7. Yagi S, Aihara K, Fukuda D, Takashima A, Bando M, Hara T, Nishimoto S, et al. Reduced ratio of eicosapentaenoic acid and docosahexaenoic acid to arachidonic acid is associated with early onset of acute coronary syndrome. Nutr J. 2015;14:111.

8. Yokoyama M, Origasa H, Matsuzaki M, Matsuzawa Y, Saito Y, Ishikawa Y, Oikawa S, et al. Effects of eicosapentaenoic acid on major coronary events in hypercholesterolaemic patients (JELIS): a randomised open-label, blinded endpoint analysis. Lancet. 2007;369(9567):10901098.

9. Kitagawa Y, Abe S, Toyoda S, Watanabe S, Ebisawa K, Murakami Y, Takahashi T, et al. Gender differences in the ratio of eicosapentaenoic acid to arachidonic acid in an inland prefecture, Tochigi: Tochigi Ryomo EPA/AA Trial in Coronary Artery Disease (TREAT-CAD). Intern Med. 2014;53(3):177-182.

10. Hiki M, Miyazaki T, Shimada K, Sugita Y, Shimizu M, Aikawa T, Ouchi S, et al. Significance of serum polyunsaturated fatty acid level imbalance in patients with acute venous thromboembolism. J Atheroscler Thromb. 2017;24(10):1016-1022.

11. Oshima Y, Niki K, Hiramoto Y, Morimoto S, Takami H, Izumi M. Serum eicosapentaenoic acid/arachidonic acid ratio is low in patients with pulmonary thromboembolism. J Nutr Sci Vitaminol (Tokyo). 2013;59(5):474-477. 